\title{
UNIVERSAL HEALTH COVERAGE: A BURNING NEED FOR DEVELOPING COUNTRIES
}

\author{
Sojib Bin Zaman*1, Naznin Hossain²
}

\begin{abstract}
Background: The term of universal health coverage (UHC) are getting popularity among the countries who have not yet attained it. Majority of the developing countries are planning to implement the UHC to protect the vulnerable citizen who cannot afford to buy the health services. Poor people living in developing countries, where there is no UHC, are bereft of getting equal health care. They have to bear a significant amount of health cost in buying different services which often causes catastrophic expenditures for an individual and a family. If a country can provide UHC, it will be possible to bring all the citizens under provision of equal and quality care. However, implementation of a UHC is not an easy phenomenon, rather it needs proper design of a good health insurance system by integrating both the public and private health care providers. The influence of good governance and a sustainable health financing system is fundamental to establish UHC in the developing countries

Keywords: Universal health care, Health insurance, Governance.
\end{abstract}

\section{Introduction}

Attainment of universal health coverage (UHC) is gaining popularity in the developing countries. Most of the developed countries have achieved UHC and their citizens are enjoying the financial benefit on health. However, majority of developing countries are still in the designing and planning phase to achieve it. For ensuring UHC in a country, Ministry of Health $(\mathrm{MoH})$ need to create rational health financing which should include risk pools under the contribution of public or private funding sources [1]. People without the UHC, need to buy essential health services in exchange of out-of-pocket expenditures. World Health Assembly have started to urge the countries to achieve UHC which can be an established method of prepayment, social health insurance, and tax-based financing [2]. However, there is no specific timetable for achieving UHC as it can take many years to decade to implement a functioning health insurance system [3]. This article aimed to discuss the role of governance and health financing for the proper functioning of UHC in developing countries.

\section{Models of Health Insurance system}

There are many taxation systems around the world. Most of the developed and middle-income countries have achieved UHC after following the model of General taxation system, Social insurance system, Private insurance system and Out-ofpocket model. Every country needs to ensure the integrated functioning of both public and private insurances in providing UHC.

1. National Health System/ Taxation system: Health care services are provided by medical doctors whose salaries are paid by the Government. Federal Government works as admin to coordinate National health system. Examples countries are England, Spain, Scandinavia, Cuba, New Zealand, Hong Kong and others. The cost of health care are funded by the taxation of the general people, and most of the services are free.
2. Bismarck model/ Social Insurance system: Most of the cases, private medical workers provide the treatment, and non-profit insurance companies finance it. The employees and employers pay the premium, and the Government regulates it. Germany, France, Switzerland, Belgium, Japan, and countries in Latin America practice social insurance system. The advantage of social insurance system is provision of a fair \& equitable treatment. However, these systems often get overloaded, failing to meet the needs of majority patients.

3. Private Insurance System: Premium are selected upon the risk of health condition for a citizen (i.e. USA). However, there are multiple ways to finance health care which includes employer-supported insurance, privately-purchased insurance, and Government-sponsored insurance. The main US Strengths are the provision of world-class health care facilities and relatively short waiting time. However, many people cannot afford to buy private insurance.

4. Out-of-Pocket Model: Individual expenses are covered by patients directly. In this model, there is no admin to monitor the whole system in collecting the money for paying the healthcare expenditure. Countries like rural parts of Africa, South East Asia, China, and some countries of South America mostly depend on out pocket expenditure model.

\section{The need of a good health system for UHC}

The establishment of a good health system is fundamental to ensure a sustainable UHC. A good performing health system consists of many interconnected parts that need to be reconciled together. Primary health care system needs to carry out some basic functions: provision of efficient health services, developing skill health workforce, good health financing, and a health system leadership [4, 5]. World Health Organization has drawn up a single framework with six clearly defined components to determine the inter-connected parts of a health system. WHO framework on building-block approach of health system includes [6]: 
- Service Delivery

- Human Resources

- Medical Products and Technologies

- Health information

- Health Financing

- Governance and Leadership

\section{Health Governance}

Highest priority has been given to Governance and leadership as it is the key factor which can maintain all the activities effectively. Without having a strong political commitment, it is not possible to strengthening a health system. Maintaining an excellent service delivery system is a fundamental need for society. The skilled workforce working with public and private entity must accompany the service provision system to build up UHC under the strong leadership of health managers.

\section{User fee and out pocket expenditure}

Out of pocket spending may cost around $19 \%$ of the expenses of total income, therefore considered to be accountable to a catastrophic expenditures [7]. However, out pocket payment is considered to be the significant source of health financing in developing countries. However, there is scope for the policymakers to consider best alternatives among different types of user fees: a combination of patient copayments and coinsurance system. Considerable arguments exist against out of pocket costs, as this system is not equitable and can hit the poorest community deterring them not to go hospital. Even it can discourage people from seeking early treatment to use preventive medicine and healthy adaptation. However, out of pocket fees bring more revenue, make patients more costconscious and can deter frivolous demand.

\section{Health financing system in developing countries}

Health financing provides the resources and economic incentives for the smooth operation of health systems in a country. Health financing system involves revenue collection, pooling of risk and purchasing system, maintaining these financial issues are also challenging. For example, Bangladesh, a country of South East Asia, gets the pooling fund mainly from three sources - the public taxes, out-of-pocket payments in the form of user fee, and foreign aid from the development partners. The Ministry of Health of a country is responsible to deal with health related budgetary allocation. Social and private insurance fees comprise a slight proportion of the total funding. In Bangladesh, household's out-of-pocket expenditure (64\%) continues to be the predominant source of financing for health costs among the others [3]. Government's revenues are collected through the tax and non-tax sources. Although most of the hospital and doctors are publicly funded, one needs to pay a high toll of money for the purpose of investigations and drug/medicine purchase. Patients need to pay a higher service fee for the private hospital and doctors, therefore, one should pay directly for the services which in turn bound the people, to fall on supplier induced demand.

\section{Challenges in providing equity of care}

Many middle to high-income countries have integrated essential health care services under the UHC. However, ensuring the provision of quality care for all population under different schemes of UHC is a challenge. High premiums and low services are the main obstacle in providing equity of care. For example, inequalities in specialized care among the beneficiaries of different insurance schemes have also been reported in the USA [8]. It is high time that Ministry of Public Health should take the initiative to reduce inequalities in health care benefits to achieve true UHC for the general population. The investment on health to ensure the sustainability, particularly health voucher programs to increase the demand for maternal and neonatal health services has reduced mortality in the developing countries [9, 10].

\section{Conclusion}

Access to healthcare is essential to all the citizens of a country. Therefore, provision of universal health coverage is a fundamental need for the developing countries. Nationwide extension of primary health care coverage, health financing, and strong political support are the proven enabling factors for achieving UHC. However, maintaining the quality, equity, and efficiency of healthcare under different schemes/premiums of UHC could pose a challenge.

\section{References}

1. Garrett L, Chowdhury AMR, Pablos-Méndez A. All for universal health coverage. The Lancet. 2009;374(9697):1294-9.

2. Luk A, Ma RCW, So WY, Kong APS, Yang X, Chow CC, et al. P-85 Metabolic syndrome identifies chronic kidney disease in Chinese patients with Type 2 diabetes \&\#x2014; a prospective study. Diabetes Research and Clinical Practice.79:S86.

3. Yates R. Universal health care and the removal of user fees. The Lancet. 2009;373(9680):2078-81.

4. Organization WH. Everybody's business-strengthening health systems to improve health outcomes: WHO's framework for action. 2007.

5. Zaman SB. Importance of Learing the Public Health Leadership. Public Health of Indonesia. 2017;3(1):1-3.

6. WHO. Monitoring the building blocks of health systems: a handbook of indicators and their measurement strategies. [Available from: http://www.who.int/healthinfo/systems/WHO_MBH SS_2010_full_web.pdf (accessed March 15, 2017).

7. WHO. National health accounts. Geneva: World Health Organization, 2007. [Available from: http://www.who.int/whosis/whostat2007_6healthsy stems_nha.pdf (accessed July 23, 2009).

8. Zhang JX, Huang ES, Drum ML, Kirchhoff AC, Schlichting JA, Schaefer CT, et al. Insurance status 
and quality of diabetes care in community health centers. American journal of public health. 2009;99(4):742-7.

9. Chowdhury S, Banu L, Chowdhury T, Rubayet S, Khatoon S. Achieving Millennium Development Goals 4 and 5 in Bangladesh. BJOG: An International Journal of Obstetrics \& Gynaecology. 2011;118(s2):36-46.

10. Zaman SB, Hossain N, Yasir Arafat SM, Sharmin S. Management of Newborn Infection: Knowledge and attitude among health care providers of selected subdistrict hospitals in Bangladesh. International Journal of Perceptions in Public Health. 2017;1(2):127-32.

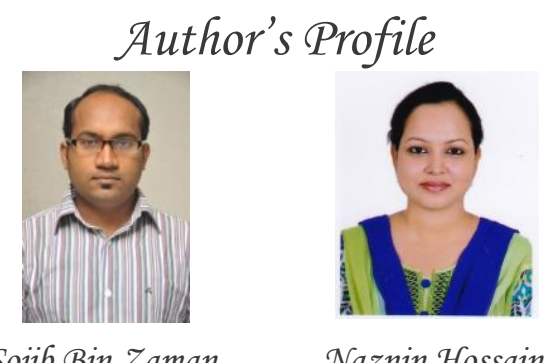

Sojíb Bin Zaman
Naznin Hossain

\section{Article Details}

\section{Author Details}

1. Maternal and Child Health Division, International Centre for Diarrhoeal Disease Research, Bangladesh.

2. Department of Pharmacology, Dhaka Medical College, Bangladesh.

\section{*Corresponding Author Details}

Sojib Bin Zaman,

Maternal and Child Health Division, International Centre for Diarrhoeal Disease Research, Bangladesh.

E-mail: sojib@icddrb.org

Date of Submission: 12/04/2016 | Date of Publishing: 17/04/2017

\section{Financial or Other Competing Interests: None}

Copyright: (C) 2017. The Author. This is an open access article under the CC BY license (http://creativecommons.org/licenses/by/4.0)

How to cite this article

Zaman SB, Hossain N. Universal Health Coverage: A Burning Need for Developing Countries. Journal Of Medical Research And Innovation. 2017;1(1):18-20. 